\title{
Entrenar la mirada
}

\author{
Negrete-Camacho JJ*
}

Trabajar en cualquier área relacionada con la salud se ha convertido en un riesgo no sólo para nosotros, sino también para nuestras familias y seres cercanos. El miedo al contagio ya no es algo a lo que sólo temen los pacientes, sino también quienes los tratan o quienes, directa o indirectamente, están involucrados en su tratamiento. La actual contingencia sanitaria nos ha llevado, con sus pertinentes proporciones, a un estado de guerra, una guerra sanitaria en la que el enemigo es tan invisible como hábil, y donde nuestras líneas de defensa desafortunadamente son insuficientes.

Transitamos hacia una nueva normalidad, en la que nuestros pacientes no sólo combaten el COVID-19, sino una abrumadora cantidad de males y padecimientos que además de amenazar el cuerpo, ponen en riesgo el alma y la mente. Los profesionales de la salud se han visto en la necesidad de resignificar su rol dentro de la sociedad, reafirmando el valor cívico de su tarea, independientemente del ramo en el que la practiquen. No estamos hablando únicamente de médicos o terapeutas, sino también de personal administrativo, científicos, investigadores, personal de laboratorios o miembros de la industria farmacéutica. Nuestra relación con la salud, al igual que nuestro entorno, se ha complejizado y va mucho más allá de la relación médico-paciente.
Esta consideración nos lleva a buscar también el apoyo del personal que ahora desinfecta nuestras áreas de trabajo y los proveedores de material de protección para el personal médico, sin los cuales sería prácticamente imposible poder atender a la población. El equipo de protección, que incluye caretas, gafas, guantes y cubrebocas como principales recursos nos lleva a superar otro reto: cómo reconfortar a nuestro paciente cuando el contacto se da en estas condiciones.

Parte esencial del tratamiento del paciente es la confianza que deposita en su médico. Además del conocimiento, se ofrece la escucha y el contacto, pero cuando debemos cubrir nuestro rostro, no sólo para protegernos a nosotros sino también al paciente, nos queda la mirada como una vía para humanizar el tratamiento. Que nuestra mirada se convierta en un vehículo que pueda transmitir el apoyo de un apretón de manos, la calidez de un abrazo o una sonrisa.

Entrenar nuestra mirada implica saber que en nuestro cuidado también va el cuidado del paciente, pero ese cuidado siempre va más allá de lo físico. La mirada es invariablemente un síntoma del alma que merece la misma protección que el cuerpo. No obviemos eso como profesionales de la salud. Que cada paciente nos ofrezca la oportunidad, no sólo de ayudar en su tratamiento hacia una cura, sino de sanar el miedo y la confusión mutua, viéndonos a los ojos.

\section{Ww: medig raphic.org. mx}

* Lic. en Psicología, Universidad de las Américas, Secretaría de Salud de la Ciudad de México.

https://dx.doi.org/10.35366/94627 doi: 10.35366/94627 